\title{
Exploring Co-Construction of Learning Environments at the Boundary of School and Work Through the Lens of Vocational Practice
}

\author{
Erica Bouw ${ }^{1,2}$ (I) Ilya Zitter ${ }^{2} \cdot$ Elly de Bruijn $^{1,2}$
}

Received: 2 September 2020 / Accepted: 2 July 2021 / Published online: 16 July 2021

(c) The Author(s) 2021

\begin{abstract}
Educational institutions and vocational practices need to collaborate to design learning environments that meet current-day societal demands and support the development of learners' vocational competence. Integration of learning experiences across contexts can be facilitated by intentionally structured learning environments at the boundary of school and work. Such learning environments are co-constructed by educational institutions and vocational practices. However, co-construction is challenged by differences between the practices of school and work, which can lead to discontinuities across the school-work boundary. More understanding is needed about the nature of these discontinuities and about design considerations to counterbalance these discontinuities. Studies on the co-construction of learning environments are scarce, especially studies from the perspective of representatives of work practice. Therefore, the present study explores design considerations for coconstruction through the lens of vocational practice. The study reveals a variety of discontinuities related to the designable elements of learning environments (i.e. epistemic, spatial, instrumental, temporal, and social elements). The findings help to improve understanding of design strategies for counterbalancing discontinuities at the interpersonal and institutional levels of the learning environment. The findings confirm that work practice has a different orientation than school practice since there is a stronger focus on productivity and on the quality of the services provided. However, various strategies for co-construction also seem to take into account the mutually beneficial learning potential of the school-work boundary.
\end{abstract}

Keywords School-work boundary · Co-constructed learning environments · Educational design $\cdot$ Discontinuities $\cdot$ Design considerations

Erica Bouw

erica.bouw@hu.nl; erica.bouw@ou.nl

Extended author information available on the last page of the article 


\section{Introduction}

To meet current-day educational and societal demands, both educational institutions and vocational practices ${ }^{1}$ are seeking to design and enact learning environments that combine the contexts of school and work. From the perspective of educational institutions, combining school-based learning with work-based learning has benefits for supporting learners' vocational competence development. Work-based learning, i.e. learning that is based on real-life work experiences, exposes learners to production methods and work requirements of actual workplaces and is therefore considered as an effective way to develop vocational competence (Sweet, 2014). From the perspective of vocational practices, combined school- and work-based programmes can be interesting to reduce skills mismatches and provide hiring opportunities (Cedefop, 2020). Thus, such combinations have benefits for individuals, vocational practices, and society as a whole (Sweet, 2014) and continue to be promoted in vocational education and training policies, both in Europe (Cedefop, 2020) and worldwide (Bahl \& Dietzen, 2019). Close collaboration between different stakeholders is seen as crucial to keep Vocational Education and Training (VET) relevant (Cedefop \& ETF, 2020).

The present study focuses on the collaboration between school and work practices in terms of 'co-construction', i.e. the process in which representatives of educational institutions and vocational practices work together to both design and enact learning environments. Other studies have referred to this process as 'collaborative design' (Akomaning et al., 2011) or 'co-development' (Wesselink \& Zitter, 2017), but in our view, the term 'co-construction' explicitly underlines the need for stakeholders to stay engaged during all phases of the design and enactment. However, the various stakeholders involved in the design process may have different expectations of the learning environment or curriculum, which can lead to tensions between the collaborating practices (Thijs \& Van den Akker, 2009). Especially in vocational education stakeholders are found to have different conceptions of learning and teaching across the practices of school and work, varying from more dualistic (viewing school and work as separate practices) to a more integrated perception of vocational teaching and learning (Sappa \& Aprea, 2014; Tyson, 2016). Moreover, representatives of the two practices may have different motives for engaging in the design. Manwaring et al., (2020) illustrates that many 'models of engagement' are possible for educators to engage with vocational practice, varying from one-off meetings, to high levels of engagement and time commitment (Manwaring et al., 2020). The present study focuses on co-construction of vocational learning environments where actors from both school and work are highly engaged in the design and enactment of the learning environment.

However, such high levels of engagement can be challenging for both school and work practices. Discontinuities can arise between the practices of school and work, which can be destabilizing for the collaboration (Akkerman \& Bakker, 2011).

\footnotetext{
1 The terms 'vocational practice' and 'work practice' are used as synonyms in this article, to refer to practices in both the private and public sector. The term includes the wide range from small- and medium-sized, to large(r) organisations and enterprises.
} 
Workplaces may have limited possibilities to support learning activities (Billett, 2014; Istance \& Kools, 2013; Nyen \& Tønder, 2018), and workplace demands tend to override pedagogical goals (Fjellström \& Kristmansson, 2019). Facilitating connectivity between work-based and school-based provisions is often chosen as a strategy to work around such limitations (Griffiths \& Guile, 2003). Facilitating connectivity means that things need to be brought together that have earlier been separated, which requires appropriate arrangements for integration (Bouw et al., 2019, 2020; Choy et al., 2018; Stenström \& Tynjälä, 2009). Viewed through the lens of educational practice, findings from recent studies suggest that frequent interaction with stakeholders from work practice during the design is crucial for connectivity (Hoeve et al., 2019). But the interaction with these stakeholders is perceived as challenging by educational practitioners, who need to develop new ways of working and be willing to "attune to the pace of the work process and environment" (Nieuwenhuis et al., 2019, p. 280). Several studies have focused on the efforts of educators in vocational education to facilitate learning at the school-work boundary (e.g. Berner, 2010; Mårtensson, 2020). Some studies have also taken a design perspective to examine the connectivity issue, highlighting the strategies that can be used by educators to design vocational curricula in close collaboration with vocational practices (Wesselink \& Zitter, 2017). Research has also shown that design strategies can support the use of the learning potential at the boundaries between school and work in vocational education (Bakker \& Akkerman, 2019). The present study aims to extend these insights by inquiring into design strategies through the lens of work practice.

More understanding is needed about design considerations through the lens of work practice to support initiatives of co-construction. Insights into design strategies of representatives of vocational practice may contribute to mutual understanding between school and work practices, which in turn may help to tackle some of the recurring connectivity problems and help to better exploit the learning potential of the school-work boundaries. The present study focuses on the designable elements of co-constructed learning environments, exploring design considerations underpinning the co-construction with educational institutions (institutions for vocational education and training and for higher professional education). The next section elaborates on co-construction between the practices of school and work, on experienced discontinuities at the boundary of the two practices, and on the designable elements of co-constructed learning environments.

\section{Theoretical Framework}

\section{School-Work Connection and Discontinuities}

The connection between 'school' and 'work' is challenged by the differences between the practices. School and work are seen as social practices with distinct historical and cultural backgrounds and objects. Work practices are mainly driven by business demands and school practices are mainly driven by their educational purpose (Poortman et al., 2014; Schaap et al., 2012; Stenström \& Tynjälä, 2009). Furthermore, school and work practices are bound by different governmental, 
legislative, cultural, and behavioural differences. For instance, school practices need to comply with government guidelines about the admittance and support of students; work practices need to comply with health and safety regulations (Flynn et al., 2016). The different intents, purposes, and outcomes between school and work practices challenge integrative opportunities for learning (Eames \& Coll, 2010; Tynjälä, 2013). The sociocultural differences between the practices have been defined as 'boundaries' (Akkerman \& Bakker, 2011). These boundaries may affect communication and the progress of actions, thus leading to discontinuity.

The concept of discontinuity in learning across practices is used when an ongoing process is somehow hampered, which can lead to unfavourable consequences (Arts \& Bronkhorst, 2020). The concept is used "when actions or interactions are not perceived as showing the desired progress or when they require substantial effort" (Bakker \& Akkerman, 2019, p. 354). During co-construction, discontinuities may be experienced when trying to connect and integrate the experiences of school and work practices. For example, discontinuities may emerge when work supervisors do not agree with the school requirements for workplace learning because these requirements are not sufficiently attuned to the profession (Bakker \& Akkerman, 2019). By studying emerging discontinuities, we might improve understanding of design considerations of representatives of vocational practices, when dealing with tensions at the school-work boundary.

Discontinuities between school and work practices have been approached at different levels. A frequently studied perspective is the individual or intrapersonal level, e.g. when students have difficulties connecting their workplace experiences to their vocational school (Tanggaard, 2007), or their (part-time) educational programme to their work life (Arts \& Bronkhorst, 2020). Next to this intrapersonal level, discontinuities between the practices of school and work can also be studied at the interpersonal level, i.e. between actors, or at the institutional level, i.e. between institutions (Akkerman \& Bruining, 2016; Bakker \& Akkerman, 2019; Bronkhorst \& Akkerman, 2016; Choy et al., 2018; Grollmann, 2018). For instance, at the interpersonal level research helped to understand 'boundary work' used by teachers during school-based vocational training to reaffirm the specificity of school practice or to reconstruct workplace experiences (Berner, 2010). Studies have also addressed the need to attune school and workplace supervision (Mikkonen et al., 2017). At the institutional level, studies have focused on the need for collaboration between schools and workplaces to reach better coherence between school and workplace learning (Aakernes, 2018), and on various forms of school-work collaboration, such as coop programmes (Coll et al., 2009).

However, most studies on discontinuities between school and work practices tend to take the learners' perspective or that of the educators from vocational institutions (Berner, 2010; Endedijk \& Bronkhorst, 2014; Mårtensson, 2020; Nieuwenhuis et al., 2019; Rintala \& Nokelainen, 2020). Little is known about school-work coconstruction from the perspective of representatives of work practice that initiate or actively participate in the co-construction of learning environments together with the vocational institutions. Considering the importance of co-construction for vocational education, it is crucial to increase understanding of the design considerations of all stakeholders, and thus also of the representatives of work practices who are 
strongly engaged in the co-construction. Hence, to contribute to scholarly work on school-work collaboration, present study takes the much less studied perspective of actors from work practice regarding the co-construction of learning environments at the school-work boundary.

\section{Designable Elements}

In the present study we explore the perspective of representatives of work practice on co-construction by eliciting their considerations about the school-work connection and about the designable elements of the learning environment. These elements influence the activities learners engage in (Bouw et al., 2019; Carvalho \& Goodyear, 2018; Zitter et al., 2016). In the present study learning environments encompass four categories of designable elements:

1) Epistemic elements are all elements related to content and tasks. These elements are based on the vocational knowing (including skills and attitudes) that is seen as worthwhile in the relevant occupational domain and about how this knowing can best be presented and structured (Carvalho \& Goodyear, 2018).

2) Spatial and instrumental elements include all physical features, such as the location (school location, work location, or third location), spaces (analogue or digital), and artefacts needed to perform the relevant tasks (Bouw et al., 2019; Zitter \& Hoeve, 2012).

3) Social elements refer to which actors are active in a learning environment and the roles they fulfil. Grouping and division of labour are also part of the social elements of the learning environment, as are suggestions on how actors might interact (Carvalho \& Goodyear, 2018).

4) Temporal elements are included in this study to illuminate the importance of considering elements related to time. Designable temporal elements include timespan and intensity of the programme, nature of the time schedule, work pace (including time pressure), and work interruptions to slow down, accelerate, or pause the work process for educational purposes (Bouw et al., 2019; Zitter \& Hoeve, 2012).

Inquiring into the designable elements of co-constructed learning environments contributes to an increased understanding of the design of vocational learning environments, particularly for the discontinuities encountered by work practice and how these might be counterbalanced. The study strives to answer the following two research questions:

- Which discontinuities are encountered in relation to the designable elements from the perspective of work practice when co-constructing learning environments at the boundary of school and work?

- Which strategies are applied by work practice to counterbalance the encountered discontinuities when co-constructing learning environments at the boundary of school and work? 


\section{Context}

The study was conducted in the context of Dutch vocational education, which encompasses two educational levels qualifying students for occupational practice (De Bruijn et al., 2017; Smulders et al., 2019): senior secondary vocational education (EQF / ISCED 2-4) and higher, or tertiary, professional education (EQF / ISCED 5-7). In the Netherlands, these educational levels are enacted by institutions for vocational education and training (VET) and by universities of applied sciences (UAS). In the Netherlands vocational education is part of the public education system and educational institutions have a strong relationship with social partners, especially in senior secondary education (De Bruijn et al., 2017). Government and social partners cooperate to provide labour marketrelevant vocational arrangements that also prepare students for participation in society and for further study. Mandatory forms of workplace learning are part of Dutch vocational curricula, intended to support learners to acquire future-proof vocational competence (Hoeve et al., 2019; Smulders et al., 2019). Thus, collaboration between 'school' and 'work' is a core aspect of Dutch vocational education, both at the system level and at the level of concrete practices. The present study focuses on collaboration at the level of concrete practices, i.e. on the institutional level of educational institutions (school practice) and vocational practices (work practice) and on the interpersonal level of the actors from both practices. Since many vocational education systems worldwide are somehow dependent on school-work collaboration, findings are expected to be relevant for researchers and practitioners (both from school and from work practices) in other countries.

\section{Method}

An interview study was carried out to capture the perspective of representatives of work practice on co-construction. In-depth, semi-structured interviews were conducted with representatives of different occupational fields, who all have ample experience with co-constructing learning environments together with institutions for vocational education in the Netherlands. This approach was chosen to explore the discontinuities through the lens of work practice and to uncover the considerations on which representatives of work practice base their design decisions.

\section{Sampling and Data Gathering}

We purposively selected a specific sample of representatives of work practice, with enough 'information power', i.e. sufficiently large and varied to elucidate the aims of the study (Malterud et al., 2016) and to establish the basic elements for 'meta-themes', i.e. overarching themes derived from the dataset (Guest et al., 
2006; Hennink et al., 2017). The sample was selected based on the following three selection criteria:

- Each participant is thoroughly familiar with co-constructing learning environments, due to their role in a profit or non-profit organisation. This role can be related to Human Resource Development (HRD), Human Resource Management (HRM), Learning \& Development (L\&D), or to the development of a corporate academy or training centre.

- Each participant has ample experience with co-constructing learning environments together with educational institutions.

- Together, participants represent a variety of vocational practices in different occupational fields and a variety of co-constructed learning environments.

Thus, next to the homogeneity in experience and background in co-constructing learning environments together with educational institutions, we also strived for diversity in terms of occupational fields and the nature of the co-construction. This was done to do justice to the differences in conceptions that representatives from different occupational fields may have (Sappa \& Aprea, 2014) and to safeguard rich data about co-construction. Each representative was or had been involved in the co-construction of multiple learning environments, leading to data being gathered on co-construction of a range of learning environment designs. Participants were selected from the extensive network of the authors' vocational research group with the help of key informants from different institutions, who brought the authors into contact with relevant participants. After potential participants indicated their interest, they were approached via e-mail by the first author with additional information about the study design and data processing and were asked to sign a consent form. After receiving their informed consent, participants were interviewed by the first author.

Individual in-depth, semi-structured interviews were conducted to gain relevant background information from the participants and to allow for a thorough understanding of the interviewees' thoughts about co-constructed learning environments. Interviews were conducted with the help of an interview guide (King, 2004). This interview guide consisted of four sections: (1) the interviewee's background (current and previous roles with the co-construction of learning environments), (2) co-constructed learning environments the interviewee is familiar with, (3) experiences during the design and enactment of these learning environments, and (4) design considerations about the epistemic, spatial, instrumental, temporal and social elements of these learning environments. Interview duration varied from 65 to $93 \mathrm{~min}$, with an average duration of $78 \mathrm{~min}$ (Table 1). A total of 550 min of interviews was recorded and transcribed. Transcriptions were condensed into reports which were member-checked by all interviewees. A few remarks were added to the reports by interviewees. These remarks were included in the analysis of the data. 


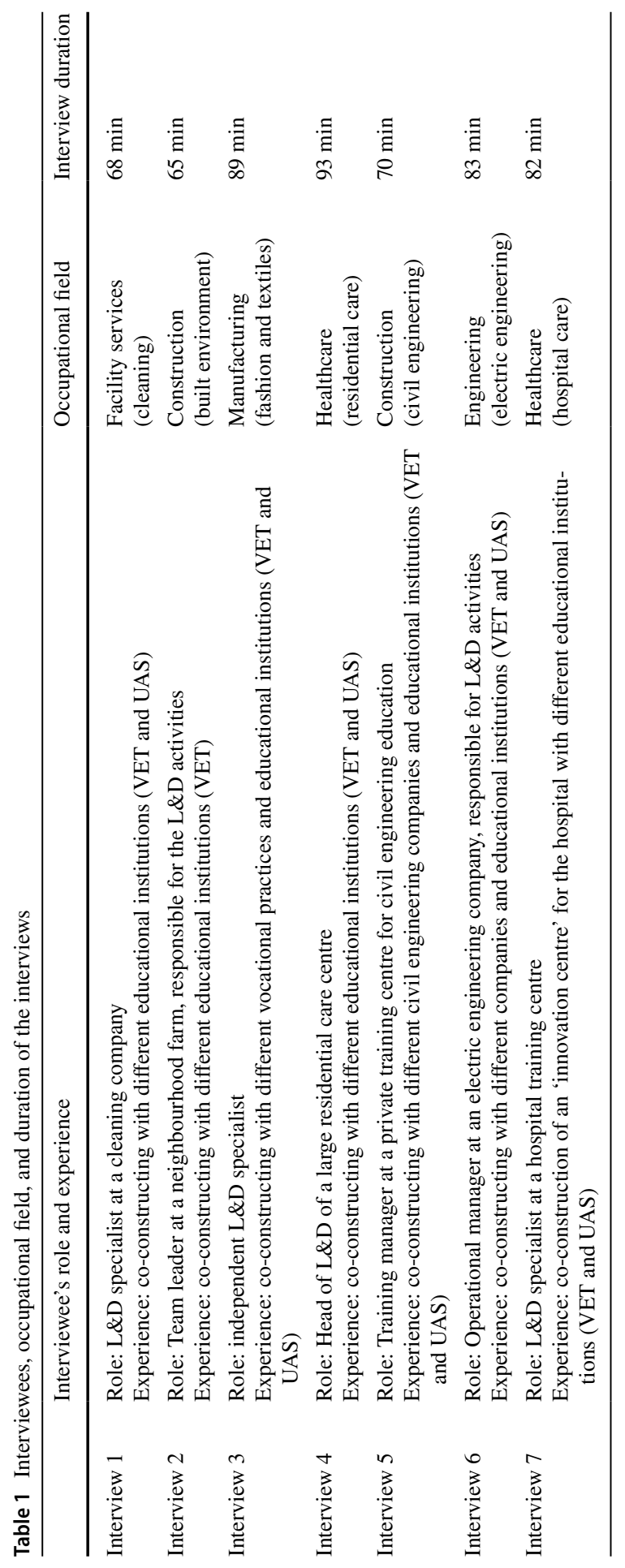




\section{Data Analysis}

Thematic analysis was applied since this is seen as a suitable approach to analyse rich and meaningful data (King et al., 2018, p. 180). We used this method to identify, organise and interpret themes in the interview data. This means that the interviews were coded by the first author through deductive and inductive coding strategies (Miles \& Huberman, 1994). We use 'code' to refer to "comments linked to extracts of text, indicating material identified by the analyst as relevant to their research question" (King et al., 2018, p. 183). Consequently, the codes related to discontinuities at the school-work boundary (question 1) and to strategies to counterbalance these discontinuities (question 2). Next to the concept of discontinuity, coding was informed by the concepts presented in the theoretical framework: the designable elements of the co-constructed learning environment (epistemic, spatial, instrumental, temporal, and social), and the two levels at which counterbalancing strategies are examined in this study: the interpersonal level (between actors) and the institutional level (between institutions). Table 2 shows the deductive codes that were stipulated in advance and their description.

Thematic analysis of the interview data led to themes based on the recurrent features in the accounts of the participants about the discontinuities that they had encountered while co-constructing learning environments and about the strategies they applied to counterbalance these discontinuities. To promote reflection and thus ensure credibility of the findings, the first and second authors held data analysis sessions in which codes and quotes from the interviews were discussed (Aarsand $\&$ Aarsand, 2019). To prevent potential bias, themes were discussed with the third author, who acted as 'critical friend' during the study (Marshall \& Rossman, 2014). The resulting themes are presented in the Findings section below. See the Appendix for Table 4 (Themes and quotes related to discontinuities) and Table 5 (Themes and quotes related to strategies).

\section{Findings}

Interview data report discontinuities related to all designable elements of the learning environment. Strategies used to counterbalance such discontinuities can be found both at the interpersonal and at the institutional level of the learning environment design.

\section{Discontinuities and Strategies Related to Epistemic Elements}

Discontinuities related to the epistemic elements seem to emerge in the learning environment when actors from school and work practices have different views on, and knowledge of, the work tasks students need to do at the workplace. It appears that actors from school practice are not always informed about the nature of the work tasks in the occupational field: "Our regional trainer hears from students that the teacher doesn't know how to do it at all" (i1, discontinuity, epistemic). 


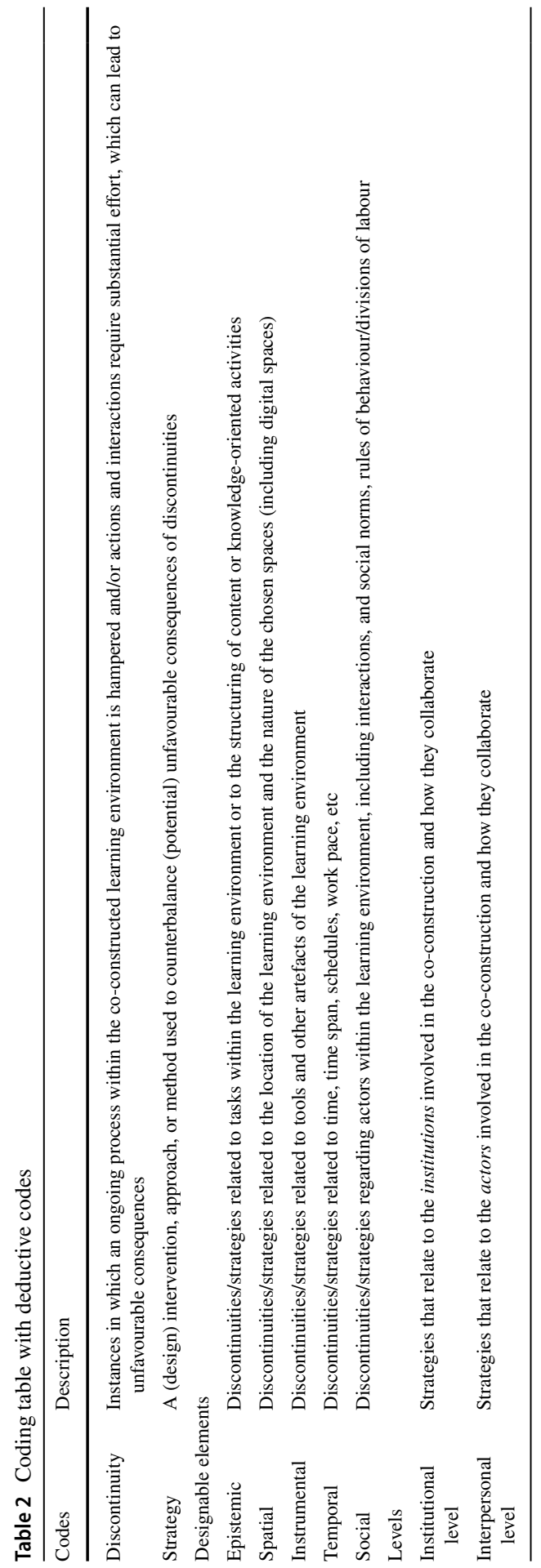


Discontinuities also appear to be related to the adaptability of the content of the learning programmes to the needs of work, i.e. the relevancy of tasks and content. Expectations are not always met, and sometimes work practice seems to want (more) consultation about the tasks that school practice sets out for the learners:

I understand that school wants them to do something, but sometimes they do not look at what they [the students] show in practice (...) So we should be consulted more often about these things, e.g. what do we find useful in professional practice? (i7, discontinuity, epistemic)

Moreover, it appears that not all learning potential is seized: interviewees (i5, i7) signal additional opportunities for students to benefit from the expertise that is available at the workplace.

We could work together every semester. That could be more fun and interesting for the mechanics teacher. But the higher education teachers seem to see this as a change, extra work. They would have to adapt the programme they have been running for 10 or 15 years to fit in, in this case, an aqueduct. That may be an extra effort for them, while they don't see the added value. (i5, discontinuity, epistemic)

In the co-constructed learning environments central to this study, schools are accountable for the content of the educational programme and the kinds of tasks learners engage in. As a consequence, the schools in question tend to adhere to the school-based training facilities for specific vocational training, even if this vocational training is also offered to employers in the workplace. Such a discontinuity is signalled at an innovation centre that is co-constructed between a hospital and several educational institutions:

We offer workshops EBP [Evidence Based Practice] for our nurses. But the students say that they have EBP lessons at school at the same time, which are not as good (...). So $80 \%$ like the module better with us, those workshops, but they still have to follow the lessons at school, because of the school credits system. (i7, discontinuity, epistemic)

To counterbalance the epistemic discontinuities one of the strategies at the interpersonal level is to add structural interactions between actors to the design, to secure more mutual consultation: "And I have also proposed that, and we do now, to structurally organise a consultation moment every 14 days" (i2, counterbalancing-epistemic, interpersonal). Such frequent interactions between actors are seen as essential to attune the tasks learners should engage in. The strategy of organising frequent interactions is also reinforced by organising proximity between actors at a specific location, where actors can meet each other:

On Wednesday they [the students and teachers] are at one of the residences. They are all there, so we [actors from work practice] also make sure that we work from that specific care location on that day, so we all see each other every week. (i4, counterbalancing-epistemic, interpersonal) 
The frequent presence of educators from school at the workplace has the advantage that these educators gain more insights into which school-related tasks might be skipped, in favour of experiences at the workplace: "I notice that with [educational institution a] it is easier to skip things, because that teacher is here more often, while with [educational institution b] they [the students] always have to go to school, even if they already learned the same lesson here" (i7, counterbalancing-epistemic, interpersonal).

At the institutional level, interviews reveal attention for both the relevance of tasks and content and avoiding a too-narrow focus on a single work practice. Interviewee 3 explains that having students rotate between different work settings helps to ensure a broad focus "not specific to one organisation or one vocational teacher" (i3, counterbalancing-epistemic, institutional). Students are afforded different work settings: "home care in [name of big town] is very different than home care in a small village (...) so they learn to work with customers from different backgrounds and with teams from different backgrounds" (i4, counterbalancing-epistemic, institutional).

Another strategy at the institutional level, intended to afford exchange of expertise, is to have teachers from the vocational institutions follow some of the same training as their (future) employees: "What we started with, is to give VET teachers the basic vocational training (...) Then they noticed that their knowledge was outdated" (i1, counterbalancing-epistemic, institutional). Or by including reciprocal exchanges in the formal agreements about the co-construction:

We have made agreements about that from the beginning, that our experts would be present in the schools more often and also that our 'lector practitioners', caretakers with a master's degree, also work with us and also teach here, in practice. (i7, counterbalancing-epistemic, institutional)

\section{Discontinuities and Strategies Related to Spatial and Instrumental Elements}

Related to spatial elements, the representatives of work practice seem to carefully consider the suitability of spaces for both work-related and school-related activities. Using spaces at the workplace for learning and instruction is seen by respondents as beneficial for vocational learning, but it also has a downside: such spaces do not always have the best facilities for school-related purposes. The hubbub of the workplace can make it hard for educators to give the needed instructions to the learners: "those multifunctional spaces that are also intended for residents are simply not always suitable for providing good training. For example, such a space is open, so you can hear rattling carts passing by on the way to the kitchen" (i4, discontinuity, spatial).

Likewise, the presence of multiple actors, both from school practice and work practice, at the same location can be a source of discontinuities: "And we don't have the right type of classroom (...). It is actually just like here (...), neighbourhood residents, volunteers, and children from school care walk around. And that is bothersome if you want to give a practical lesson" (i2, discontinuity, spatial). Such spatial discontinuities are encountered when the emergent activity in the learning 
environment does not match with the needs of the workplace, such as the need of patients for quiet spaces at a care centre:

People with dementia benefit from a space that is quiet and predictable. How does that relate to a student's learning process? We have somebody assisting for the meals, we have a qualified caretaker, and also a teacher coaching a student: how do we keep the place nice and quiet? (i4, discontinuity, spatial)

To counterbalance discontinuities related to the spatial elements of the design, a strategy at the institutional level is the purposeful selection of spaces and artefacts for specific tasks. For instance, a school-based space is selected for training specific nursing procedures: "I mean we also have nursing manikins, but they [the school] have a bit more volume (...). And they have all the materials that are cleaned properly and so yes, that was simply the best [option]" (i4, counterbalancing-spatial, institutional). Sometimes other locations are visited to allow students to experience specific tasks or materials, e.g. pouring concrete (civil engineering, i5) or cleaning specific floors (cleaning, i1).

Concerning the artefacts, interview data expose discontinuities related to tools and instruments being outdated when work practice is not sufficiently involved in the physical setup of the learning environment:

You sometimes see that in retail: they build a shop in a school. Then they have an archaic cash register there. Or they [students] still have to check the stock using a pen and paper, which never happens in practice anymore. So as soon as they [the school] have linked that practice to it, it is immediately outdated. (i2, discontinuity, instrumental)

When work practice and school practice join forces to build a learning environment, such as a lab, they can purposefully select tools and materials that are upto-date: "We [the company] set up a lab together with a VET institution, not with the equipment that was left over from the company 20 years ago (...), but with the equipment that was current at the time" (i6, counterbalancing-instrumental, institutional).

Another strategy for the same purpose is to involve other practices in the learning environment. For example, company suppliers are involved in the learning environment to inform learners about state-of-the-art products, such as the newest cash register systems in retail (i3) or the most efficient cleaning tools in facility services (i1).

\section{Discontinuities and Strategies Related to Temporal Elements}

Concerning the temporal elements of the learning environment, discontinuities are reported that arise due to differences between the schedules of school and work practice. Representatives of work practice seem to expect flexibility in scheduling, but, as interviewee 2 states, the school schedule can be hard to deviate from: "It has to be done very quickly, but at fixed times. It has to be that Friday and that Wednesday and Tuesday, because it is scheduled on those days. I mean: there's no flexibility in the schedules." (i2, discontinuity, temporal). 
Another discontinuity relates to the differences between the practices of school and work with respect to how far ahead activities are planned. Educational institutions seem to work with different planning horizons than work practice:

They work per school period and then, really, two weeks before the next period starts, they request if our regional trainer can be made available for two halfdays a week. We are used to planning and organising such things much longer ahead. (i1, discontinuity, temporal)

Besides the planning horizon, a discontinuity regarding the temporal elements has to do with the need for consultation about students' productivity. It happens that school decides to have students spend less time at work, without consulting the people from the vocational practice:

That is really annoying for us because it means that they can work less in practice, they are less productive, and well, that must be budgeted differently. And since they inform us last minute, I cannot change the planning on time. (i4, discontinuity, temporal)

A strategy to counterbalance discontinuities related to time is to reach an agreement about when students can be expected to be productive. This is done at the institutional level through formal agreements, and at the interpersonal level by discussing mutual expectations. Interviewee 4 explains that at the care centre the students are not considered as part of the workforce during the first three months of their employment:

They get their salary, but they don't have to be productive. We say this explicitly, and we also hear the workplace supervisors say this amongst them and to the students "take your time (...) just sit down, observe, register what happens, because now you have time for that; in a while, there will not be [enough time]". (i4, counterbalancing-temporal, institutional)

\section{Discontinuities and Strategies Related to Social Elements}

A discontinuity that emerges about the social elements of the learning environment relates to the availability of actors to perform the needed roles in the learning environment. For instance, when there are no educators from school available to guide or monitor learners at work: "And we noticed that that group was too big, and we had to step in, while it should be the vocational teacher, who is prepared for this task... So then we no longer had a win-win situation" (i2, discontinuity, social). A similar discontinuity is signalled when actors from work cannot be assigned to guide learners because this interferes too much with their regular tasks, e.g. care tasks in healthcare (i4).

Furthermore, interview data reveal that the connection between school practice and work practice sometimes depends on too few actors who fulfil a role as broker, while other actors do not have a clear role in the learning environment or do not perform their role in line with the expectations from work practice: 
We have several contact persons within [name of educational institution], who are very positive and very enthusiastic, but the people behind them are sometimes sceptical, they wait and see. Some pioneers take a lot of effort and are very enthusiastic and think along very well (...), but then, when they have to pass it on to others, it becomes difficult. (i1, discontinuity, social)

The limited availability of actors and the need for actors to balance educational goals and business demands can lead to role conflicts. This is manifested, for instance, by the experience split between the role of workplace supervisor and the role of employee, in this case of caretaker:

Workplace supervisors really experience that as a split. On the one hand, they want to supervise the student, they want to take time for that, they think that the student deserves it and that they are training a good colleague for the future. But when there are sick people and there is no one attending to your patient, what then? (i4, discontinuity, social)

Role conflicts are also signalled concerning the role of learners. When schoolrelated activities are concentrated on a 'school day' at the workplace, this can lead to learners abandoning their professional roles and switching to their student role, which can trigger unwanted school-like behaviour:

They really consider the school day as 'school'. And it is striking to see that people of our age - we do recruit people up to sixty in the programme - that they actually behave as students. They come in too late, they immediately start smoking again, they start doing all kinds of things on the edge of what is, and what is not acceptable, while you would not expect that. (i4, discontinuity, social)

To counterbalance discontinuities regarding role conflicts (social) and ensure that 'learning' is not overruled by 'working', a strategy at the institutional level is to design new roles, such as work supervisors exempted from work duties: "So now we have also started working with fully exempted supervisors (...) We have recruited ten people for this, all of whose work consists of supervising in practice" (i4, counterbalancing-social, institutional).

Table 3 below shows the themes related to discontinuities and counterbalancing strategies that were distinguished in the interview data for each of the designable elements.

A more encompassing strategy at the institutional level, which is aimed at counterbalancing multiple discontinuities, is to develop new practices that integrate aspects of both school and work practices. Different varieties are reported. One variety is to develop a flexible model of co-construction, that can be adapted to the needs of different educational institutions. This implies that the vocational practice can engage either in a basic model of engagement with a school, e.g. providing the workplace setting for workplace learning, or the vocational practice can participate more actively in the design and enactment of co-constructed learning environments and even take the lead in the organisation of the learning environment: 


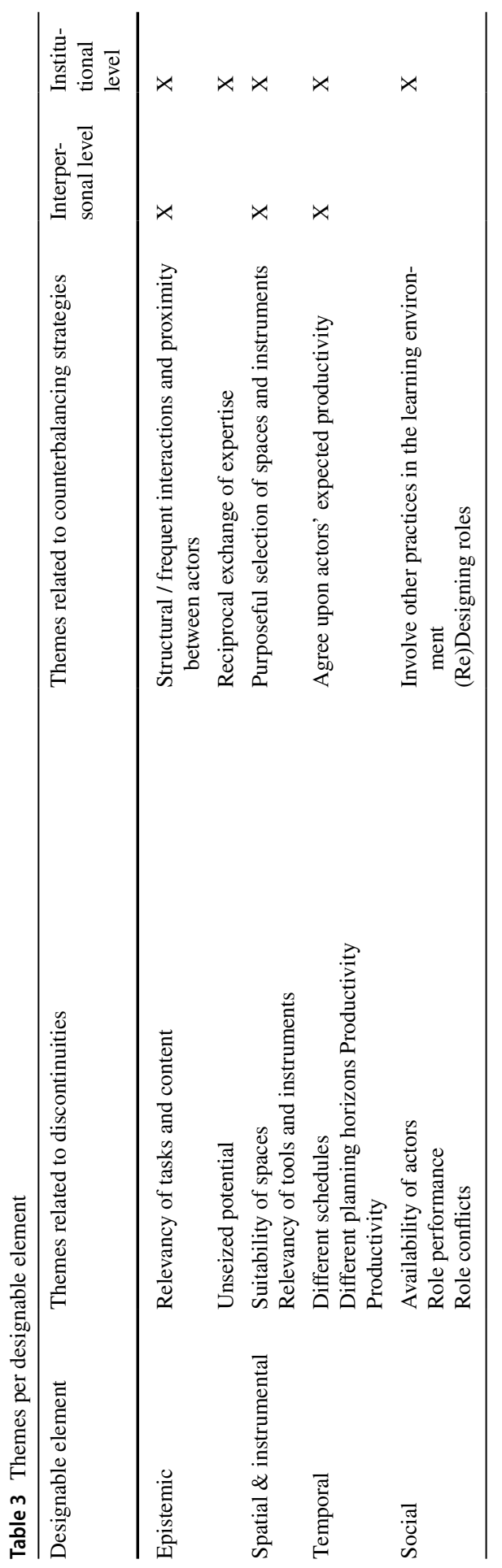


We can do it in multiple ways: our regional trainer can give specific vocational training at the school, we can organise excursions, we can give guest lessons, we can take the lead during the ten weeks of basic vocational training, or not. In fact, these are all variants that we can be agreed upon per school, how we will organise it. (i1, counterbalancing multiple, institutional)

A variation to this strategy is to establish a new organisational unit in which work and school practices are more strongly connected. Such a unit can be part of a larger organisation, as is the case with the care centre (i4) and the hospital (i7), or a new organisation in itself, as is the case with the training centre for civil engineering (i5):

But that carpenter who comes from there [public vocational educational institution], who is actually the residential carpenter, is totally different from the one they [civil engineering companies] ask for. So there was nothing, so then they [the companies] set up an academy to ensure that there was a skilled inflow [of industrial carpenters]. (i5, counterbalancing multiple, institutional)

Such an institutionalised practice can be formed with one school, to limit the amount of different educational institutions that actors from the vocational practice need to adapt to, or with several schools. Interviewee 4 explains why they chose the first option: "They [the supervisors] had to deal with all kinds of [school] systems. Well, that is not necessarily a guarantee for good guidance, so I wanted to bring more uniformity, and just do business with only one institution". (i4, counterbalancing multiple, institutional).

In all three organisational units that integrate school and work practices, studentsemployees are employed by this unit until they finish their education. This entails that they are not pressured to be productive in the learning environment right from the start. Interviewee 7 explains the difference between students having an employment contract with the training unit versus being employed directly at one of the hospital wards:

And that is the beauty of it, I think, that all students, whether they have a learning-employment contract or an internship agreement, that they have a contract with us [training unit], because then we do not have that hassle of students being put on the work schedule within two weeks. Because that used to be the way it was. (i7, counterbalancing-multiple, institutional)

Interviewee 4 also speaks about the advantages of employing the students: it allows them to monitor employees both in their roles of learner and of caretaker:

The great thing is of this construction, is that we can intervene incredibly quickly if we notice that a student is not doing well (...) And yes, if the teacher says "gosh, that person stands out in the group, he does not seem very motivated", then it is also very easy on our side to check how the student functions in practice. (i4, counterbalancing multiple, institutional).

The strategy of integrating the practices of school and work also aims at counterbalancing discontinuities by allowing learners to combine their learning and working tasks within the learning environment: 
Students are really stimulated to look at: I want to find out something, I have a patient and I run into something, I want to look it up in literature, then they also get time for it. They need to say how long they will be working on it, what they want to do, and how they will provide feedback to the other students in the afternoon, so that it becomes a learning moment for the group. And then we also look at: which patient room were you linked to, what care were you giving, who will take over your care tasks when you are working on another learning task? (i7, counterbalancing multiple, institutional)

\section{Conclusions and Discussion}

The purpose of the present interview study was to improve understanding of the co-construction of learning environments in vocational education through the lens of vocational practice. Interviews were held with representatives of vocational practices in different occupational fields in the Netherlands. From the findings it appears that when co-constructing learning environments, discontinuities can be found relating to all designable elements: epistemic (nature and relevancy of tasks and content), spatial (suitability of spaces), instrumental (use of up-todate tools and instruments), temporal (schedules, planning horizons and expected productivity) and social elements (availability of actors, role conflicts and role performance). Findings further show that these discontinuities are counterbalanced with purposeful strategies at the interpersonal and institutional levels of the design. Results suggest that at the interpersonal level frequent interactions and proximity can contribute to better attuning the school-related and work-related activities that emerge in the learning environment. At the institutional level, the formalisation of school-work agreements and the integration of the two practices into new organisational units seem to be helpful strategies to meet the demands of both school and work practices.

The signalled discontinuities and the strategies to counterbalance these discontinuities support the concept of 'boundary crossing learning mechanisms' as developed by Akkerman and Bakker (Akkerman \& Bakker, 2012; Bakker \& Akkerman, 2019). These learning mechanisms are useful to understand how learning can be triggered at the school-work boundary. Findings confirm that it helps to demarcate the responsibilities of actors from the different practices and to use artefacts to explicate the agreements between the practices involved. Furthermore, the strategy of organising joint meetings for actors from school and work practices might indeed stimulate mutual reflection. The findings also substantiate that roles can be added or adapted to ensure that roles are complementary to one another. Lastly, findings verify the emergence of new practices that combine the affordances of school and work practices. Such new practices seem to be helpful for supporting the continuous processes of coordination and reflection that are needed to align the interests of stakeholders from school and work 
and to support learners to cross the boundaries between the contexts. Further empirical studies are needed to enrich understanding of the strategies adopted by school and work practices to make better use of these learning mechanisms and thus effectively mine the learning potential of learning environments at the school-work boundary.

The identified strategies in the present study to counterbalance discontinuities between the practices of school and work are similar to bridging strategies found in other studies. Relating to (dis)continuity between two work practices, a study in the context of product introduction showed that integration of product development and production can be enhanced by intrapersonal and interpersonal boundary crossing (Gustavsson \& Säfsten, 2017). Our study further enriches these insights by taking a specific design perspective and by including the institutional level. Furthermore, the main strategy that we found at the institutional level is in line with previous findings about establishing continuity between in-school and out-of-school contexts: one of the ways to establish continuity is by creating hybrid practices in which actors from both contexts interact (Bronkhorst \& Akkerman, 2016).

The present study confirms that work practice has a different orientation than school practice, needing to take into account work productivity and the quality of the services provided. Nevertheless, it also shows that strategies employed by work practice can be simultaneously focused on the learning taking place. Findings include empirical data on co-construction that show that much attention is paid to the interplay between working and learning, e.g. by protecting studentemployers against high work pressure, affording them ample time to learn in different work settings, and by developing new roles for workplace actors, aimed at stimulating and monitoring learning activities at the workplace. This contrasts with some other studies about learning environments at the school-work boundary in which learners reported experiencing little interest from work practice in their work performance and employability (e.g. Strickland et al., 2001). In our study, several of the reported strategies are explicitly aimed at supporting learners to perform well both as students and (future) employees. This is particularly evident in learning environments in which students have an employment contract. The different status of the student-employees allows them to spend dedicated time on learning activities that are not directly linked to their work tasks, or even to the work practice they are currently functioning in. Students are thus trained to be able to perform in other practices as well. This broad approach to learning while working suggests that work-based training centres can be co-constructed in a way that meets both school and work demands.

Stakeholders engaged in the co-construction of vocational education may use the presented insights to discuss and reflect on the design of learning environments at the school-work boundary. Such discussions and reflections may help to create a shared understanding for the (re)design and 'co-maintenance' of learning environments. At the institutional level, the presented insights may support policy 
development and accountability by facilitating discussions on the ambitions concerning the school-work connection and the constructive alignment of different learning environments in an educational programme (Tynjälä et al., 2021). At the interpersonal level, the findings encourage facilitation of continuous exchange between the actors involved during both the design and the enactment of a learning environment. Moreover, the manuscript pinpoints potential tensions in the school-work collaboration and offers insights into strategies to compensate for these tensions. The findings can help actors from school and from work to explicitly exchange ideas on the characteristics of learning environments and to carefully consider which specific designable elements (such as concrete tasks and artefacts) best fit with the decisions that are made at a more strategic level, thus contributing to the coherence between different levels of the design.

In the present study we examined the boundary between the social practices of school and work. However, a variety of distinct social practices exist within these practices and new boundaries can emerge. Any organisation can encompass different practices. A hospital, for instance, encompasses multiple wards that can each be seen as a separate social practice. Similarly, in civil engineering each group of experts represents a different practice (construction, land development, hydraulic engineering, etc.). The differences between such practices may be experienced as boundaries that impact the activities in the learning environment. It would be interesting to further examine the discontinuities that are encountered at the boundaries of 'practices within practices' and the efforts that are undertaken to bridge them. Moreover, new boundaries may also emerge when new practices are co-constructed at the boundary of school and work. A work-based training unit that employs student-employees can be viewed as a 'school practice' within the vocational practice, when the orientation shifts more towards learning than towards working. It may be interesting to explore whether such a training centre is indeed experienced as 'school' by the stakeholders involved.

A potential limitation of our study might be that its specific contextual and explorative nature may limit the applicability of the findings to other educational contexts. Differences between (educational systems of) countries make it difficult to simply apply findings from educational research studies from one country to the other. Nonetheless, since vocational education worldwide is based on more or less the same educational purposes and since such education calls for engagement between partners to provide experiences across educational and practice settings (Billett, 2011), findings are expected to be of interest to an international audience of researchers and practitioners.

With regards to the methods, our study illustrates that the exploration of considerations of a small, but purposefully selected, sample of representatives with ample experience can help to uncover relevant overarching themes (King et al., 2018), that may be of interest to other researchers. Moreover, the sample that we selected was heterogeneous enough to allow for insights across occupational fields and types of learning environments and homogenous enough to explore the 
perspective of representatives of work practice on co-constructing learning environments. All representatives are or have been involved in the co-construction of multiple learning environments. With the relative heterogeneity, we wanted to do justice to the fact that in different occupational fields, different views of school-work connectivity may be in place, e.g. in the field of business and administration actors may have a less integrated view of vocational learning and teaching across practices (Sappa \& Aprea, 2014). Such different views may affect the way learning environments are co-constructed. However, although participants were active in different occupational fields, the sample was relatively homogenous in terms of participants' background: all participants shared a background in learning and development and/or had ample experience with designing for learning in vocational practices. In addition, our focused study objectives and a semi-structured interview approach allowed us to distinguish overarching themes across the interviews (Hennink et al., 2017). Nevertheless, additional qualitative and quantitative studies from both perspectives would be useful to validate and supplement the findings.

Notwithstanding the limitations above, the present study adds to the body of knowledge about co-constructing learning environments at the school-work boundary by explicitly exploring the perspective of work practice. Thus, the present study contributes to mutual understanding between the practices, which is needed to support initiatives of co-construction and mine the learning potential of the school-work boundary. The insights presented in this study may be useful both for researchers who want to gain a deeper understanding of co-constructing vocational learning environments and for practitioners and experts who continuously strive to improve such learning environments to meet the demands of current-day society. 


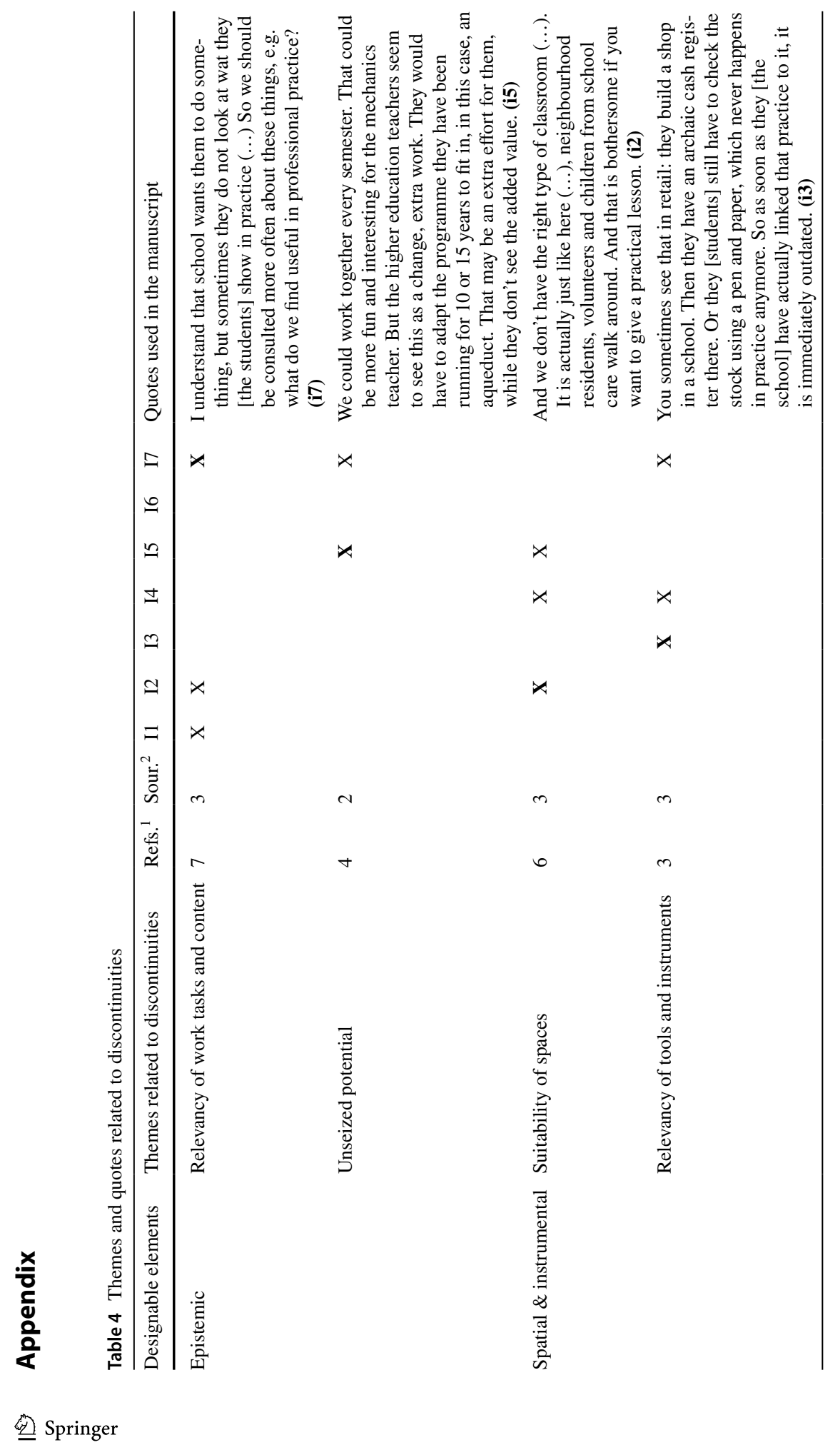




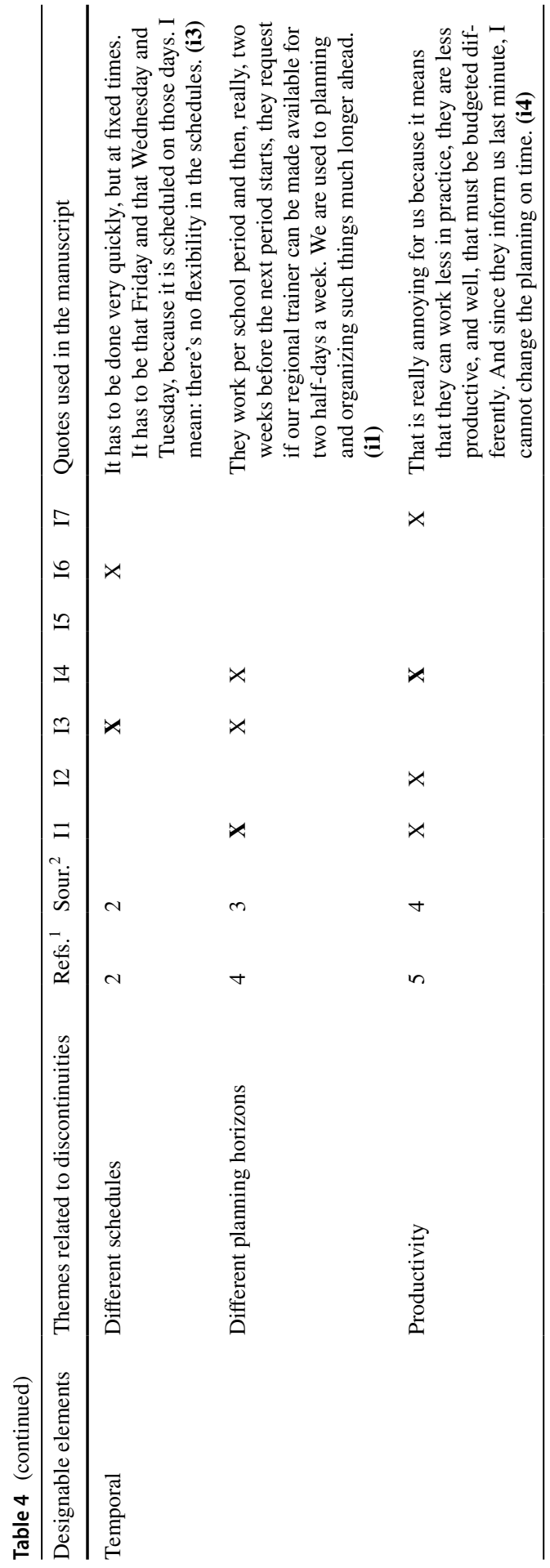




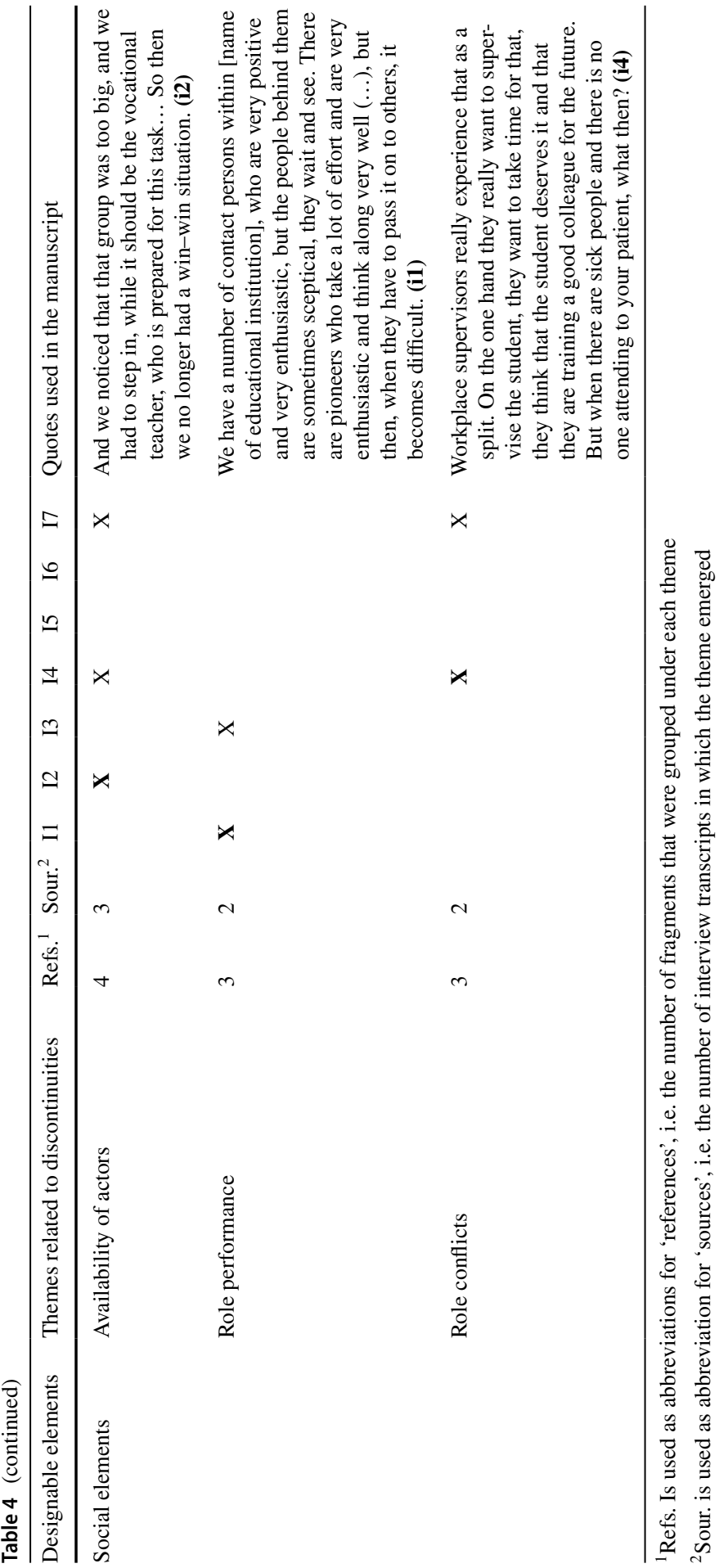




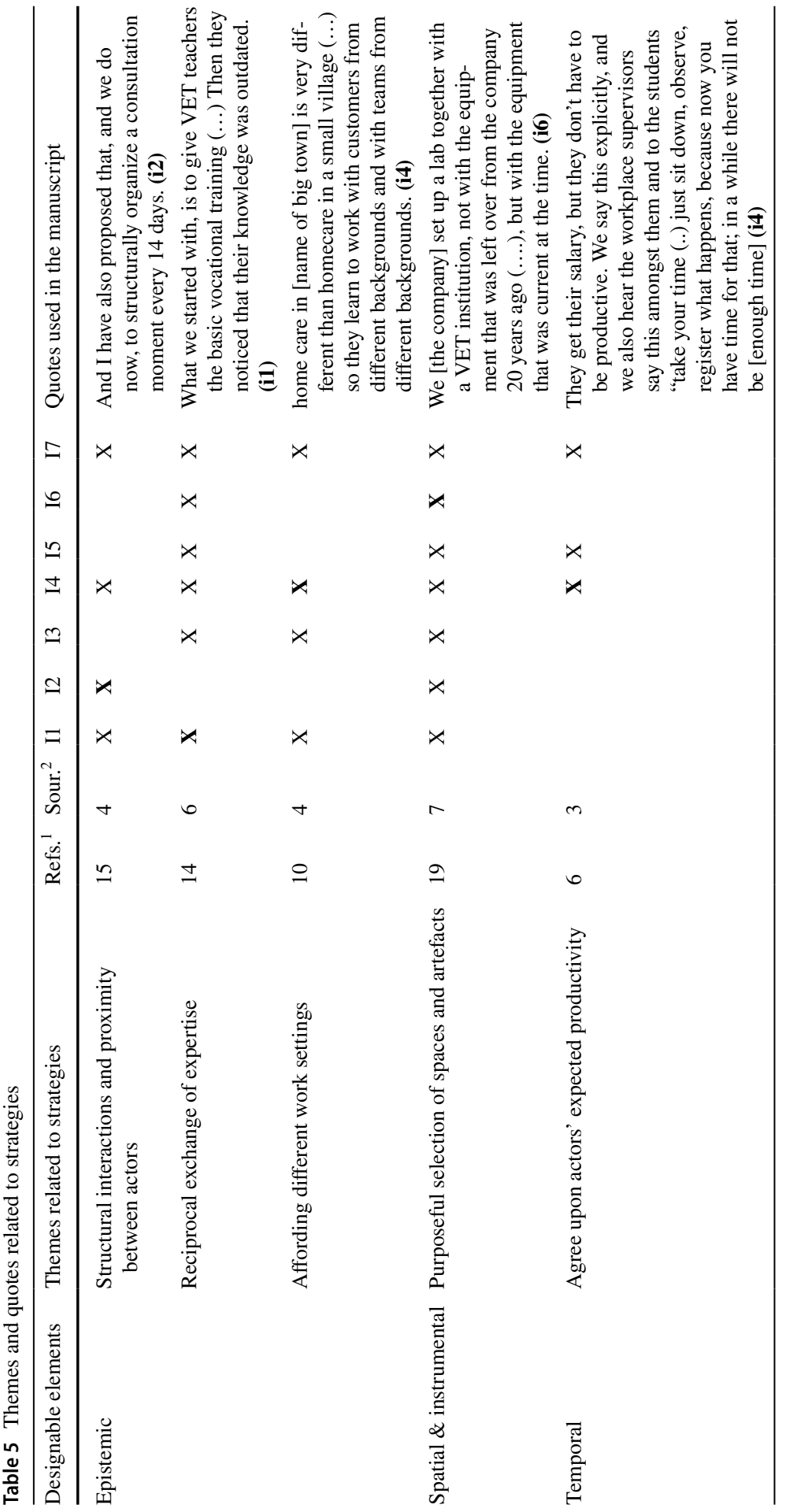




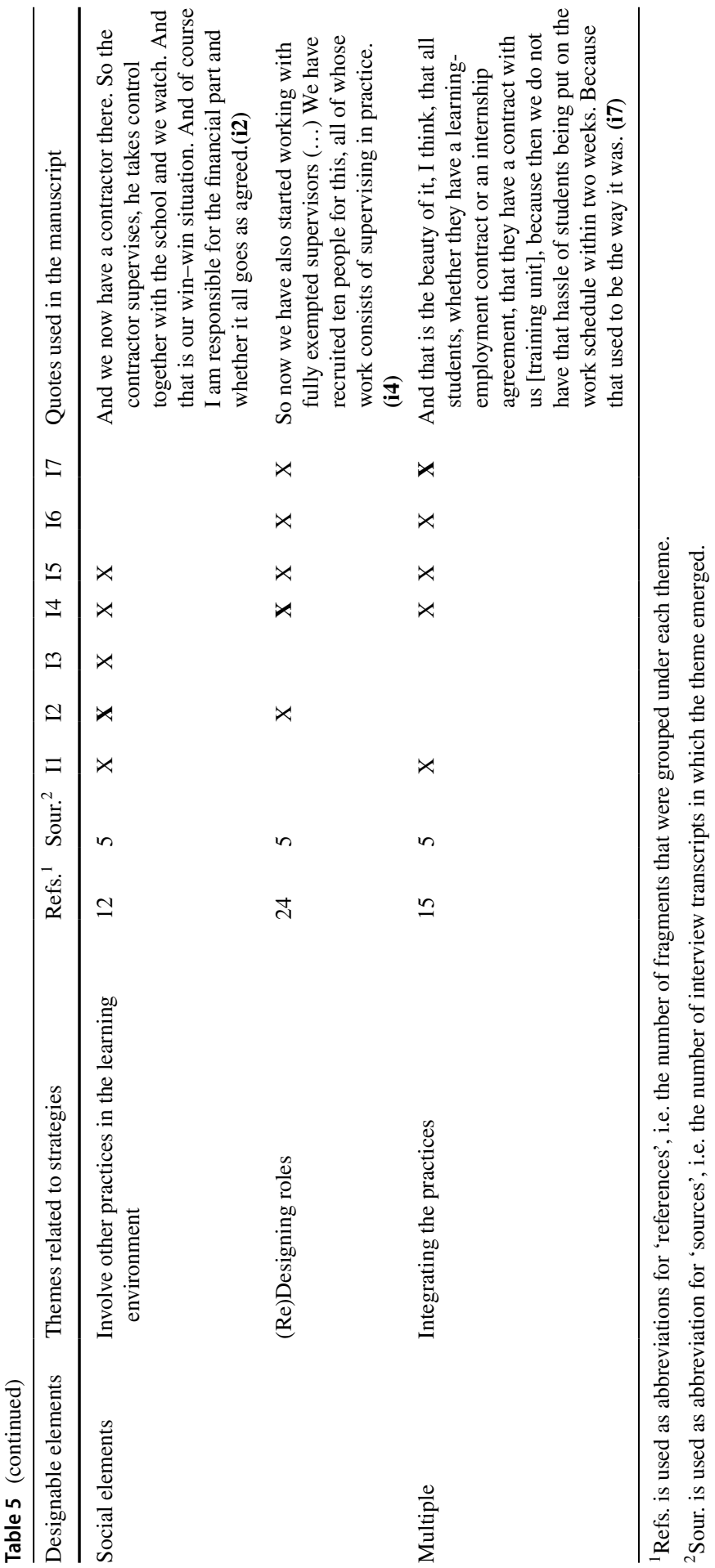


Open Access This article is licensed under a Creative Commons Attribution 4.0 International License, which permits use, sharing, adaptation, distribution and reproduction in any medium or format, as long as you give appropriate credit to the original author(s) and the source, provide a link to the Creative Commons licence, and indicate if changes were made. The images or other third party material in this article are included in the article's Creative Commons licence, unless indicated otherwise in a credit line to the material. If material is not included in the article's Creative Commons licence and your intended use is not permitted by statutory regulation or exceeds the permitted use, you will need to obtain permission directly from the copyright holder. To view a copy of this licence, visit http://creativecommons.org/licen ses/by/4.0/.

\section{References}

Aakernes, N. (2018). From school to work: Coherence between learning in school and learning in workplaces for apprentices in the Media graphics programme in Norway. Nordic Journal of Vocational Education and Training, 8(1), 76-97. https://doi.org/10.3384/njvet.2242-458x.188176

Aarsand, L., \& Aarsand, P. (2019). Doing data analysis - Collaboration, creativity and critique. In M. Honerod Hoveid, L. Ciolan, A. Paseka, \& S. Marques da Silva (Eds.), Doing educational research. Overcoming challenges in practice. Sage.

Akkerman, S., \& Bakker, A. (2011). Boundary crossing and boundary objects. Review of Educational Research, 81(2), 132-169. https://doi.org/10.3102/0034654311404435

Akkerman, S., \& Bakker, A. (2012). Crossing boundaries between school and work during apprenticeships. Vocations and Learning, 5(2), 153-173. https://doi.org/10.1007/s12186-011-9073-6

Akkerman, S., \& Bruining, T. (2016). Multilevel boundary crossing in a professional development school partnership. Journal of the Learning Sciences, 25(2), 240-284. https://doi.org/10.1080/10508406. 2016.1147448

Akomaning, E., Voogt, J. M., \& Pieters, J. M. (2011). Internship in vocational education and training: Stakeholders' perceptions of its organisation. Journal of Vocational Education and Training, 63(4), 575-592. https://doi.org/10.1080/13636820.2011.590222

Arts, M., \& Bronkhorst, L. H. (2020). Boundary crossing support in part-time higher professional education programs. Vocations and Learning, 13(2), 215-243. https://doi.org/10.1007/ s12186-019-09238-9

Bahl, A., \& Dietzen, A. (Eds.). (2019). Work-based learning as a pathway to competence-based education. A UNEVOC network contribution. Federal Institute for Vocational Education and Training.

Bakker, A., \& Akkerman, S. (2019). The learning potential of boundary crossing in the vocational curriculum. In D. Guile \& L. Unwin (Eds.), The Wiley Handbook of Vocational Education and Training (Issue July, pp. 349-372). https://doi.org/10.1002/9781119098713.ch18

Berner, B. (2010). Crossing boundaries and maintaining differences between school and industry: Forms of boundary-work in Swedish vocational education. Journal of Education and Work, 23(1), 27-42. https://doi.org/10.1080/13639080903461865

Billett, S. (2011). Vocational education: Purposes, traditions and prospects. Springer Science and Business Media. https://doi.org/10.1007/978-94-007-1954-5

Billett, S. (2014). Integrating learning experiences across tertiary education and practice settings: A socio-personal account. Educational Research Review, 12, 1-13. https://doi.org/10.1016/j.edurev. 2014.01.002

Bouw, E., Zitter, I., \& De Bruijn, E. (2019). Characteristics of learning environments at the boundary between school and work - A literature review. Educational Research Review, 26, 1-15. https://doi. org/10.1016/j.edurev.2018.12.002

Bouw, E., Zitter, I., De Bruijn, E. (2020). Designable elements of integrative learning environments at the boundary of school and work: A multiple case study. Learning Environments Research 1-31 https:// doi.org/10.1007/s10984-020-09338-7

Bronkhorst, L. H., \& Akkerman, S. (2016). At the boundary of school: Continuity and discontinuity in learning across contexts. Educational Research Review, 19, 18-35. https://doi.org/10.1016/j.edurev. 2016.04.001

Carvalho, L., \& Goodyear, P. (2018). Design, learning networks and service innovation. Design Studies, 55, 1-27. https://doi.org/10.1016/j.destud.2017.09.003 
Cedefop. (2020). On the way to 2020: Data for vocational education and training policies. In Cedefop research paper (Issue 76). Publications Office of the European Union. https://doi.org/10.2801/54941

Cedefop and ETF. (2020). The importance of being vocational: Challenges and opportunities for VET in the next decade discussion paper. https://doi.org/10.2801/009305

Choy, S., Wärvik, G. B., \& Lindberg, V. (2018). Considerations for the integration of students' experiences. In S. Choy, G.-B. Wärvik, \& V. Lindberg (Eds.), Technical and vocational education and training (pp. 345-365). Springer. https://doi.org/10.1007/978-981-10-8857-5_18

Coll, R. K., Hodges, D., Bhat, R., \& Ram, S. (2009). An exploration of the pedagogies employed to integrate knowledge in work-integrated learning. Journal of Cooperative Education \& Internships, 43(1), 14-35.

De Bruijn, E., Billett, S., \& Onstenk, J. (2017). Vocational education in the Netherlands. In E. De Bruijn, S. Billett, \& J. Onstenk (Eds.), Enhancing teaching and learning in the Dutch vocational education system (Vol. 18, pp. 3-36). Springer. https://doi.org/10.1007/978-3-319-50734-7_1

Eames, C., \& Coll, R. K. (2010). Cooperative education: Integrating classroom and workplace learning. In Learning Through Practice (pp. 180-196). Springer. https://doi.org/10.1007/978-90-481-3939-2_ 10

Endedijk, M. D., \& Bronkhorst, L. H. (2014). Students' learning activities within and between the contexts of education and work. Vocations and Learning, 7(3), 289-311. https://doi.org/10.1007/ s12186-014-9116-X

Fjellström, M., \& Kristmansson, P. (2019). Constituting an apprenticeship curriculum. Journal of Curriculum Studies, 51(4), 567-581. https://doi.org/10.1080/00220272.2019.1616115

Flynn, M. C., Pillay, H., \& Watters, J. J. J. (2016). Industry-school partnerships: Boundary crossing to enable school to work transitions. Journal of Education and Work, 29(3), 309-331. https://doi.org/ 10.1080/13639080.2014.934789

Griffiths, T., \& Guile, D. (2003). A connective model of learning: The implications for work process knowledge. European Educational Research Journal, 2(1), 56-73. https://doi.org/10.2304/eerj. 2003.2.1.10.

Grollmann, P. (2018). Varieties of "duality": Work-based learning and vocational education in international comparative research. In S. Choy, G.-B. Wärvik, \& V. Lindberg (Eds.), Integration of vocational education and training experiences: Purposes, practices and principles (Vol. 29, pp. 63-82). Springer Nature. https://doi.org/10.1007/978-981-10-8857-5_4

Guest, G., Bunce, A., \& Johnson, L. (2006). How many interviews are enough?: An experiment with data saturation and variability. Field Methods, 18(1), 59-82. https://doi.org/10.1177/1525822X05279903

Gustavsson, M., \& Säfsten, K. (2017). The learning potential of boundary crossing in the context of product introduction. Vocations and Learning, 10(2), 235-252. https://doi.org/10.1007/ s12186-016-9171-6

Hennink, M. M., Kaiser, B. N., \& Marconi, V. C. (2017). Code saturation versus meaning saturation: How many interviews are enough? Qualitative Health Research, 27(4), 591-608. https://doi.org/10. $1177 / 1049732316665344$

Hoeve, A., Kuijer-Siebelink, W., \& Nieuwenhuis, A. F. M. (2019). Innovative work-based learning for responsive Vocational Education and Training (VET). In D. Guile \& L. Unwin (Eds.), The Wiley handbook of vocational education and training (pp. 415-432). John Wiley \& Sons, Inc. https://doi. org/10.1002/9781119098713.ch21

Istance, D., \& Kools, M. (2013). OECD work on technology and education: Innovative learning environments as an integrating framework. European Journal of Education, 48(1), 43-57. https://doi.org/ 10.1111/ejed.12017

King, N. (2004). Using interviews in qualitative research. In C. Cassell \& G. Symon (Eds.), Essential Guide to Qualitative Methods in Organizational Research (pp. 11-22). SAGE Publications.

King, N., Brooks, J., \& Tabari, S. (2018). Template analysis in business and management research. In M. Ciesielska, D. Jemielniak (Eds.), Qualitative methodologies in organization studies (pp. 179-206). Palgrave Macmillan. https://doi.org/10.1007/978-3-319-65442-3_8

Malterud, K., Siersma, V. D., \& Guassora, A. D. (2016). Sample size in qualitative interview studies: Guided by information power. Qualitative Health Research, 26(13), 1753-1760. https://doi.org/10. $1177 / 1049732315617444$

Manwaring, R., Holloway, J., \& Coffey, B. (2020). Engaging industry in curriculum design and delivery in public policy teaching: A strategic framework. Teaching Public Administration, 38(1), 46-62. https://doi.org/10.1177/0144739419851155

Marshall, C., \& Rossman, G. B. (2014). Designing qualitative research. In Sage publications. (6th ed.). 
Mårtensson, Å. (2020). Creating continuity between school and workplace: VET teachers' in-school work to overcome boundaries. Journal of Vocational Education and Training. https://doi.org/10.1080/ 13636820.2020.1829009

Mikkonen, S., Pylväs, L., Rintala, H., Nokelainen, P., \& Postareff, L. (2017). Guiding workplace learning in vocational education and training: A literature review. In Empirical Research in Vocational Education and Training (Vol. 9, Issue 1). https://doi.org/10.1186/s40461-017-0053-4

Miles, M. B., \& Huberman, A. M. (1994). Qualitative data analysis: An expanded sourcebook (Vol. 2nd). Sage Publications. https://doi.org/10.1016/0149-7189(96)88232-2

Nieuwenhuis, A. F. M., Hoeve, A., Kuijer, W., \& Peeters, A. (2019). Bridging demands on education, innovation and practice-based research; The case of Dutch vocational and professional education. In Work-based learning as a pathway to competence-based education - A UNEVOC Network contribution (pp. 273-287). BIBB.

Nyen, T., \& Tønder, A. H. (2018). Development of vocational skills through integration of practical training periods in school based vocational education in Norway. In Technical and Vocational Education and Training (Vol. 29, pp. 227-241). Springer. https://doi.org/10.1007/978-981-10-8857-5_12

Poortman, C. L., Reenalda, M., Nijhof, W. J., \& Nieuwenhuis, A. F. M. (2014). Workplace learning in dual higher professional education. Vocations and Learning, 7(2), 167-190. https://doi.org/10.1007/ s12186-014-9111-2

Rintala, H., \& Nokelainen, P. (2020). Vocational education and learners' experienced workplace curriculum. Vocations and Learning, 13(1), 113-130. https://doi.org/10.1007/s12186-019-09229-w

Sappa, V., \& Aprea, C. (2014). Conceptions of connectivity: How swiss teachers, trainers and apprentices perceive vocational learning and teaching across different learning sites. Vocations and Learning, 7(3), 263-287. https://doi.org/10.1007/s12186-014-9115-y

Schaap, H., Baartman, L., \& De Bruijn, E. (2012). Students' learning processes during school-based learning and workplace learning in vocational education: A review. Vocations and Learning, 5(2), 99-117. https://doi.org/10.1007/s12186-011-9069-2

Smulders, H., Cox, A., \& Westerhuis, A. (2019). Vocational education and training in Europe: Netherlands. Cedefop ReferNet VET in Europe reports 2018.

Stenström, M.-L., \& Tynjälä, P. (2009). Towards integration of work and learning: Strategies for connectivity and transformation. Springer Nature. https://doi.org/10.1007/978-1-4020-8962-6

Strickland, A., Simons, M., Harris, R., Robertson, I., \& Harford, M. (2001). On- and off-job approaches to learning and assessment in traineeships and apprenticeships. Australian Apprenticeships: Research Readings, 199-219.

Sweet, R. (2014). Work-based bearning: A handbook for policy makers and social partners in ETF partner countries. In European Training Foundation.

Tanggaard, L. (2007). Learning at trade vocational school and learning at work: Boundary crossing in apprentices' everyday life. Journal of Education and Work. https://doi.org/10.1080/1363908070 1814414

Thijs, A., \& Van den Akker, J. (2009). Curriculum in development. Stichting Leerplan Ontwikkeling (SLO).

Tynjälä, P. (2013). Toward a 3-P model of workplace learning: A literature review. In Vocations and Learning (Vol. 6, Issue 1). https://doi.org/10.1007/s12186-012-9091-Z

Tynjälä, P., Beausaert, S., Zitter, I., \& Kyndt, E. (2021). Connectivity between education and work: Theoretical models and insights. In E. Kyndt, B. Simon, \& I. Zitter (Eds.), Developing Connectivity Between Education and Work: Principles and Practices. Routledge.

Tyson, R. (2016). When expectations clash: Vocational education at the intersection of workplace and school. Interchange. https://doi.org/10.1007/s10780-015-9271-5

Wesselink, R., \& Zitter, I. (2017). Designing competence-based vocational curricula at the schoolwork boundary. In E. De Bruijn, S. Billett, \& J. Onstenk (Eds.), Enhancing teaching and learning in the Dutch vocational education system (pp. 175-194). Springer. https://doi.org/10.1007/ 978-3-319-50734-7_9

Zitter, I., \& Hoeve, A. (2012). Hybrid learning environments: Merging learning and work processes to facilitate knowledge integration and transitions. OECD Education Working Papers, 81. https://doi. org/10.1787/5k97785xwdvf-en

Zitter, I., Hoeve, A., \& De Bruijn, E. (2016). A design perspective on the school-work boundary: A hybrid curriculum model. Vocations and Learning, 9(1), 111-131. https://doi.org/10.1007/ s12186-016-9150-y 
Publisher's Note Springer Nature remains neutral with regard to jurisdictional claims in published maps and institutional affiliations.

Erica Bouw has conducted the research reported in this manuscript as a $\mathrm{PhD}$ student at Open University of the Netherlands. She now has a PhD in educational sciences. Her research focuses on the design of learning environments at the boundary of school and work. She also works as a teacher at HU University of Applied Sciences Utrecht and is affiliated with the Research Group Vocational Education.

Ilya Zitter is professor at the HU University of Applied Sciences Utrecht and affiliated with the Research Group Vocational Education and the Teaching \& Learning Network (for university-wide learning and development). Main area of expertise is the design of learning environments at the boundary of school and work in vocational and higher professional education, with as research methods applied, qualitative research and design science research.

Elly de Bruijn is a specialist in research on teaching and learning processes in the context of vocational education. Design research on innovative teaching practices and accompanying questions on student results and teacher professionalism are her special interests. She is research director and holds a professorship on Vocational Education at the HU University of Applied Sciences Utrecht and is also professor of vocational education at the Open University of the Netherlands.

\section{Authors and Affiliations}

\section{Erica Bouw ${ }^{1,2}$ (I) Ilya Zitter ${ }^{2}$ E Elly de Bruijn ${ }^{1,2}$}

Ilya Zitter

ilya.zitter@hu.nl

Elly de Bruijn

elly.debruijn@ou.nl

1 Open University of the Netherlands, PO Box 2960, 6401 DL Heerlen, The Netherlands

2 HU University of Applied Sciences, PO Box 14007, 3508 SB Utrecht, The Netherlands 